THE EFFECT OF TEMPERATURE VARIATION ON THE SEX COMPOSITION AND GROWTH OF PEOCILLA MELANOGASTER OFFSPRING

Elsayed A. Khallaf', D. Passia', Ahmed M. Abdeen', Feryal A. El- Mesady

1- Zoology Dept, Minufiya University, Egypt.

2-Anatomy II Dept,Dusseldorf University, Germany-

3- Zoology Dept, Mansoura University, Egypt.

Key words : Temperture, sex composition, growth, offspring, Peocilia.

\title{
ABSTRACT
}

The sexual differentiation of $P$. melanogaster embryos was 1 examined among fish kept in glass aquaria $(80 \times 40 \times 35 \mathrm{~cm})$ at 23 , 26 and $29^{\circ} \mathrm{C}$ with a $\mathrm{pH}=6.5$.

Analysis of variance of the data revealed a significant variation (at the $5 \%$ level) of sex composition relative to increase of water temperature. Two mathematical representations ivere predicted for males and females.Accordingly, the degrees at which all males, or all females, or 1:1 sex ratio had been determined was $18.95,32.01$ and $25.4^{\circ} \mathrm{C}$ respectively.

The mechanism of this temperature effect on the sex ratio was discussed where growth of fish was suspected to have piayed a role in this process.

\section{Sex Ratio}

\section{INTRODUCTION}

The near equal production of males and females by most organisms has fascinated biologists since the days of Darwin. In 1929, Fisher pointed out that, since each individual arising from sexual reproduction, males equal that of parental females. Therefore, if the population sex ratio deviates from equal numbers of males and females, pairs producing the rarer sex will have a selective advantage until the population sex ratio is equalized. This statistical mechanism maintaining equal sex ratios has been later demonstrated by several authors (Shaw \& Mohler 1953; Kolman 1960; MacArthur 1965; Verner 1965; Myers, 1978; Conover, 1984 and Olivier \& Kaiser, 1997). However, environmental factors such as $\mathrm{pH}$ may affect sex ratio in 
some Cichlids and Poeciliids (Rubin, 1985).

According to Romer and Beisenherz (1995) a correlation between sex ratio of offspring of 33 different species of Apistogramma and temperature at certain $\mathrm{pH}$-level could be demonstrated with high significance. At low temperature $\left(23^{\circ} \mathrm{C}\right)$ the sex ratio of offspring of 32 Apistogramma species was skewed towards femaies, whereas at high temeprature $\left(29^{\circ} \mathrm{C}\right)$ towards males and at a temperaure of $26^{\circ} \mathrm{C}$ the number of males and females was approximately balanced. However, Apistogramma cacti showed a reversed response to temperature. The previous authors declared that temperature could influence sex ratio of offspring during development within the first weeks of life.On the other hand, in Apistogramma, sex ratio was influenced by $\mathrm{pH}$-level, too.

Numerous experimental studies have recently reported, however, that environmental sex determination (ESD) is prevalent among poikilothermic vertebrates. In these vertebrates, incubation temperature determines the course of primary sex differentiation (and thereby the sex ratio of progeny) during a specific period of embryonic or larval development. In some species, lower temperatures produce males and higher temperatures produce females (e.g.turtles) while in others, the pattern is reversed (Lizards, alligators, fishes).

The live-bearing fishes of the family Poeciliidae are widely known to exhibit unusual sex ratios. Examples of some reports include Poecilia reticulata (Haskins et al.1961), Gambusia mani (Krumholz, 1963), Heterandria formosa (Colson, 1969), Poeciliopsis monacha (Moore, 1971) and Gambusia holbrooki (Vargas \& Sostoa, 1996). Three other examples of fishes with temperature sex dtermination have been recently studied in the laboratory: (1) the Atlantic silver-side, Menidia menidia (Conover \& Kynard, 1981; Conver \& Heins, $1987 \mathrm{a}, \mathrm{b}$ and Conover et al.1992), in which some genotypes produced excess of males at high temperatures and excess of females at low temperatures, while others in the same population were strictly genetic sex determination (GSD); (2) the hermaphrodite, Rivulus marmoratus (Harrington, 1967, 1971), a fish which at its normally warm tropical or subtropical temperatures fertilizer itself and produces hermaphroditic offspring, but when reared at $20^{\circ} \mathrm{C}$, produces $75 \%$ males; and (3) Poeciliopsis lucida, which is a polymorphic fish with genotypes that have either genetic sex determination (GSD) or temperature sex determination (TSD). As 
THE EFFECT OF TEMPERATURE VARIATION ON THE SEX COMPOSITION AND GROWTH OF PEOCILIA AELANOG.ASTER

OFFSPRING

dorumented by Sullivan and Schuiz (1986) and Schuiz (1993).

In this paper, the effect of temperature on the sex ratio of $P$. melanogaster is assessed.

\section{MATERIAL AND METHODS}

Adult males and females of Poecilia melanogaster were collected from large fish tanks containing various fish species at the Department of Zoology II,University of Dtisseldorf (Prof. Dr. Greven, H.,Germany). Fishes were separated and kept in glass aquaria $(80 \times 40 \times 35 \mathrm{~cm})$ with constantly aerated water. Fresh water plants e.g. Hydrilla and Pistia, were provided to match the natural habitat of the fish. Fishes were maintained under $12 \mathrm{hrs}$. light $12 \mathrm{hrs}$. dark schedule. They were fed daily with commercially available fish food (Tetramin" "Tetra-Werke,Melle, Germany). The experimental aquaria were kept a $23 \pm 1^{\circ} \mathrm{C}, 26 \pm 1^{\circ} \mathrm{C}$, or $29 \pm 1^{\circ} \mathrm{Cand} \mathrm{pH}=6.5$. The temperature was checked four times daily, and heating was carried out by heaters, while cooling was reached by use of ice, if such need arised during the experiment.

Statistics:

The influence of the applied temperatures $\left(23^{\circ} \mathrm{C}, 26^{\circ} \mathrm{C}\right.$ and $29^{\circ} \mathrm{C}$ ) on the sex ratios of the offspring were examined statistically, by a two-way ANOVA analysis (Neter and Wasserman,1974).In order to describe the interaction between gender and temperature, a correlation analysis is applied (Pearson Product Moment Correlation).

\section{RESULTS}

Effect of temperature variation on the sex composition and growth of offspring:

A two-way analysis of variance (ANOVA) revealed a significant variation $(\mathrm{P}<5 \%)$ of sex composition relative to the increase of water temperature in favour of males over females among offspring of that fish. The overall average for males was $54 \%$ and $46 \%$ for female with a standard error for either sex of $( \pm 0.6)$. It is worth to mention that the total number of offspring did not show any significant variation with temperature difference (Tabies 1,2 and 3).

The change in sex ratio due to temperature variation was statistically examined as follows: 
The relationship between average percentage of male offspring and average temperature used in the experiment was found to follow a straight line (Fig.1) and predicted as follows: $\mathrm{Pm}=$ $145.1653+7.6592 \mathrm{Tr}=0.997$. where $\mathrm{Pm}=$ percentage of number of males among total number of offspring, and $T=$ average water temperature in centigrades. From this equation, the quantity $-a / b(Y-$ intercept value divided by the slope value as defined in this equation) of this relationship will define the temperature at which all offspring would be females. Which was found to be $18.95 \mathrm{C}^{0}$.

While the relationship between percentage of females and variation of water temperature was found to behave similarly (Fig. 2), and followed the mathematical equation:-

$$
\begin{aligned}
& \text { Pf }=245.161-7.6592 \\
& T r=0.997
\end{aligned}
$$

Where Pf $=$ percentage of number of females among total number of offspring, $\mathrm{T}=$ average water temperature in centigrades.

Again, the quantity $-\mathrm{a} / \mathrm{b}$ here, in this relationship, will define the average temperature at which all offspring would be all males; this was found to be $32.01 \mathrm{C}^{0}$. In addition, by extrapolation at the $50 \%$ of either sex it appears that the temperature at which the sex ratio 1:1 would be reached is $25.4 \mathrm{C}^{\circ}$. However, the average water temperature that would be effective in producing $1: 1$ males to females, could be calculated by summation of both temperature extremes and dividing by two (2). This was found to be $25.45 \mathrm{C}^{0}$ which is not different from the extrapolated prediction.

The growth in length with age of the $P$. melanogaster offsprings with variation of temperature is shown in Table 4. From this table, it appears that there is a significant correlation between age and length of the offsprings at either the lower on higher temperature tanks, for either sex. However, the difference in growth rate of the offsprings in either tanks is more apparent during the first 10 days of life, than in the next 10 to 50 days. Thus, either males or females of the $23^{\circ} \mathrm{C}$ tank have higher growth rate than those of the $29^{\circ} \mathrm{C}$ tank. The difference is in favour of growth of the $23^{\circ} \mathrm{C}$ tank fish in the first 10 days of life, as well as during the next 40 days (10-50). However, this difference in growth among males in the first period is more than double (0.04) that of hose fish of the second period (0.0198). On the other hand, the difference in growth of females in the first period is more than four times that of the second period. 


\section{DISCUSSION}

Poecilia melanogaster is a viviparous top-minnow belonging to the family Poecliidae. This family is native to the New World (Southern United States and West Indies) where their distribution is principally tropical, [Gunther, 1866; Rosen and Bailey, 1963 Innes, 1979; Nelson, 1984 and Meyer et al.1985]. The present preliminary investigation of sex ratio, in the viviparous Poeciliid teleost Poecilia melanogaster have clearly demonstrated that; sex ratio and thus very probably sex differentiation is temperature dependent in this species.

The statistical analyses of the mathematical representation of the relationship for the species under study has proved significantly the effect of temperature on determination of sex ratio. Such a finding was previously reported in a different species (Apistogrmma) by Romer and Beisenherz (1995). However, it is only in this study, at temperature $18.95^{\circ} \mathrm{C}$ the offspring would be all females, and that at $32.01^{\circ} \mathrm{C}$ they would be all males. The equally estimated sex ratio was at $25.4^{\circ} \mathrm{C}$. Although such quantification is not so far present in the literature, genotypic sex determination has been shown in many fish species. Environmental sex determination (BSD) in fish has been shown so far in a few species (Conover and Kynard, 1981;Rubin, 1985; Sullivan and Schultz, 1986; Schultz, 1993; and Romer and Beisenherz, 1995).

In the Atlantic silverside fish Menidia menidia, the temperature affects primary sex determination during the larval development. Most offspring produced under lower temperature regimes of the early breeding season become females, while most offspring produced at the higher temperatures prevailing during. the late breeding season become males. However, the fish Menidia peninsula showed that the sex is biased towards females at cold temperature $\left(11-19 \mathrm{C}^{\circ}\right)$, while at warm fluctuating temperature (17$25^{\circ} \mathrm{C}$ ) the ratio is 1: lor favoured males (Conover and Kynard, 1981; Conover, 1984 and Middaugh and Hemmer, 1987).

Moreover, in the poeciliid, Xiphophorus helleri the sex ratio was affected by $(\mathrm{pH})$ and water temperature (Rubin, 1985); and the poeciliid fish Poeciliopsis lucida (Sullivan and Schuiz 1986 and Schuiz,1993).In these species, sex appears to be determined by genetic factors, temperature level and genotype-temperature interaction (Price, 1984) The response of sex ratio to temperature was 
adjusted upward or downward, perhaps by selection of sexdetermining genes sensitive to higher (or lower) temperatures (Sullivan and Schuiz, 1986 \& Mair et al.1997).

The hypothesis of environmental sex determination (ESD) suggests environmental determination of sex whenever the environment affects the relative fitness of males and females differentially (Charnov and bull, 1977 and Charnov et al.,1981). In addition, parental adjustment of sex ratio in offspring during the period of care may affect the reproductive success of male and female offspring differently (Trivers and Willard,1973). Adaptive variation in environmental and genetic sex determination in Menidia menidia according to this hypothesis could be demonstrated by Conover and Heins $(1987 a, b)$. Such mechanism is now suspected throughout the fish growth as emphasized in this study. Thus, on considering the growth in length of the offspring, statistical analysis showed differences which may throw some light on the effect of temperature on this fish. The first result that comes out of these analyses is that, fish kept in $29^{\circ} \mathrm{C}$ tanks have low growth rate than those kept in $23^{\circ} \mathrm{C}$ tanks. The second result is that, there is a conspicuous decrease in growth in both sexes after the day 10 to 50 after birth.

However, a third outcome of these results is that males have though slight, but lower growth rate than females. Could it be that lowering growth rate of offspring, due to raised temperature, activates, in some unknown way, the biological convertion of sex from females into males. No other evidence, so far, could be found in the previous literature confirming such finding.

\section{REFERENCES}

Bacci, G. (1965). Sex Determination Pergamon Press, Oxford, New York. (Quoted from Conover, D.O (1984). Adaptive significance of temperature - dependent sex determination in a fish. Amer. Nat., 123: 297-313.

Charnov, E.L. and Bull, J. J. (1977). When is sex environmentally determined? Natur., 266: 828-830.

Charnov, E.L.; Los-den Hartogh,R.L.;Jones, W.T.and Van Den Assen, J.(1981).Sex ratio evolution in a variable environment. Natur.. 289: 27-33. 
THE EFFECT OF TEMPERATURE VARIATION ON THE SEX COMPOSITION AND GROWTH OF PEOCILIA MELANOGASTER

Colson,C.M.(1969).Effect of daylength and temperature on the reproduction of Heterandria formosa Ph.D. dissertation. Univ. Florida, Gainesville.

Conover,D.O.(1984). Adaptive significance of temperature-dependent sex determination in a fish. Am. Natur., 123: 297-313.

Conover,D.O. and Heins, S.W. (1987a). Adaptive variation in environmental and genetic sex determination in a fish. Natur., 326: 496-498.

Conover, D.O. and Heins, S.W. (1987b). The environmental and genetic components of sex ratio in Menidia menidia (Pisces:Atherinidae). Copeia.,732-743.

Conover, D.O. and Kynard, B.E.(1981). Environmental sex determination: Interaction of temperature and genotype in a fish. Sci.,213: 577-579.

Conover, D.O.; Van Voorthees, D.A. and Ehtisham, A. (1992). Sex ratio selection and the evolution of environmental sex determination in laboratory populations of Menidia menidia. Evolut.,46(6): 1722-1730.

Giinther, A.(1866).A catalogue of the fishes in the British Museum. London, 6:368 pp.

Harrington, R.W., J.R. (1967). Environmentally controlled induciton of primary male gonochorists from eggs of the selffertilizing hermaphroditic fish Rivulus marmoralus Poey. Biol. Bull.,132: 174-199.

Harrington, R.W., JR. (1971). How ecological and genetic factors interact to determine when self-fertilizing hermaphrodites of Rivulus marmoratus change into functional secondary males, with a reappraisal of intersexuality among fis.es. Copeia, 389-432. 
Haskins,C.P.; Haskins,E.F.; McLaughin,J.J.A. and Hewitt.R.E. (1961).Polymorphism and Population structure in Lebistes reticulatus, an Ecological Study. In: (Blair, W.F. ed.) Vertebrate Speciation. Pp.320-395Univ.Texas.Press. Ustin.

Innes, W.T.(1979). "Exotic Aquarium Fishes" (by Dr. Innes, W.T. the original eds.) with70 new colour photographs. Live-bearers. Pp. 274-288. T.F.H. Publications, Inc., Ltd.

Jones, C.L.W.; Kaiser, H.and Hecht,T.(1998). Effect of shelter, brood stock number and sex-ratio on juvenile production in the sword tail Xiphophorus helleri under intensive culture conditions. J. World Aquat. Soc., 29: 1-92.

Kolman, W.(1960). The mechanism of natural selection for the sex ratio. Amer. Nat .,94: 373-377.

Krumholz, L.A. (1963). Relationships between fertility, sex ratio, and exposure to predation in populations of the mosquito fish, Gambusia manni. Hubbs at Bimini, Bahamas. Int. Rev. Ges. Hydrobiol.,48: 201-256.

MacArthur,R.H.(1965).Ecological consequences of Natural selection. In : Theoretical and Mathematical Biology. (Waterman H., and Morowitz., H.J. ed). pp. 388-397. Blaisdell, New York.

Mair,G.C.;Abucay,J.S.;Skibinski,D.O.F.; Abella,T.A.and Beardmore, J.A. (1997). Genetic manipulation of sex ratio for the large-scale production of all-male Tilapia, Oreochromis niloticus. Can J. Fish. Aquat. Sci., 54: 396-404.

Meyer, M.K.; Wischnath, L. and Foerster, W. (1985). Poeciliidae.In: (Meyer, M.K., Wiischnath, L.; Foerster, W. eds). Lebendgebarende Zierfische.,pp. 126-393. Mergus, Melle.

Middaugh,D.P.and Hemmer, M.J. (1987). Influence of environmental temperature on sex-ratio in the Tide water Silverside, Menidia peninsulab (Pisces:Atherninidae).Copeia:958-964. 
Moore,W.S.(1971).The population ecology of unisexual-bisexual species complexes in the genus Poeciliopsis (Pisces: Poeciliidae). Ph.D. dissertation. Univ. Connecticut. Storrs.

Myers,J.H. (1987). Sex ratio adjustment under food stress: Maximization of quality of numbers of offspring?. Amer. Nat., 112: $381-388$.

Nelson, J.S.(1984).Fishes of the World. A modem classificaiton of all major groups of Fishes. 213-424 (Wiley, J. and Sons ed.) New york. Chiichester. Brisbane. Toronto. Singapore.

Neter, J. and Wasserman. W. (1974). Applied linear statistical model 842 pp. (by Richard, D. irwin, INC). Homewood, Illinois. Georgetown, Ontario, USA.

Olivier, A. and Kaiser, H. (1997). A comparison of growth, survival rate, and number of marketable fish produced of sword tails, Xiphophoms helleri Heckel Family Poeciliidae, between two types of culture systems.Aquaculture Res.,28: 215-221.

Price, D.J. (1984). Genetics of sex determination in fishes-a brief review. In: Fish reproduciton: Strategies and Tactics"(Potts, G.W. and Wooton, R.J. eds) .pp. 77-89. Academic press. London.

Reinboth, R. (1975). Intersexuality in the Animal Kingdom. SpringerVerlag, Berlin.

Romer,U. and Beisenherz, W. (1995). Modifikatorische Geschloechtsbestimmung durch. Temperature and $\mathrm{pH}$-Wert bei Buntbarschen der Gattung. Apistogramma. In: Greven, $\mathrm{H}$. Riehl, P. (eds) Fortpflanzungs biologie derAquarienfische. 261-266. Birgit Schmettkamp, Bornheim.

Rosen,D.E. and Bailey, R. M. (1963). The poeciliid fishes (Cyprinodontifomes); their structure, zoogeography and systematics. Bull. Amer. Mus. Nat. Hist., 126: 1-176. 
Rubin, D.A.(1985). Effect of $\mathrm{pH}$ on sex ratio in Cichlids and a poeciliid (Teleostei). Copeia, $]: 233-235$.

Schultz, R.J. (1993). Genetic regulation of temperature -mediated sex ratios in the livebearing fish Poeciliopsis Lucida. Copeia, 4:1148-1151.

Shaw, R.F. and Mohler, J.D. (1953). The selective advantage of the sex ratio. Amer. Nat., 87:337-342.

Sullivan, J.A. and Schultz, R.J.(1986).Genetic and environmental basis of variable sex ratios in Iaboratory strains of Poeciliopsis lucida. Evol., 40:152-158.

Trivers, R.L. and Willard, D.E. (1973). Natural selection of parental ability to very sex-rato. Sci., 179: 90-92.

Vargas, M.J. and Sostoa,A.D.,(1996). Life history of Gambusia holbrook:(Pisces,Poeciliidae) in the Ebro delta (NE Iberian Peninsula). Hydrobiol.,341: 215-224.

Verner, J. (1965). Selection for sex ratio. Amer. Nat.,99: 419-421. 


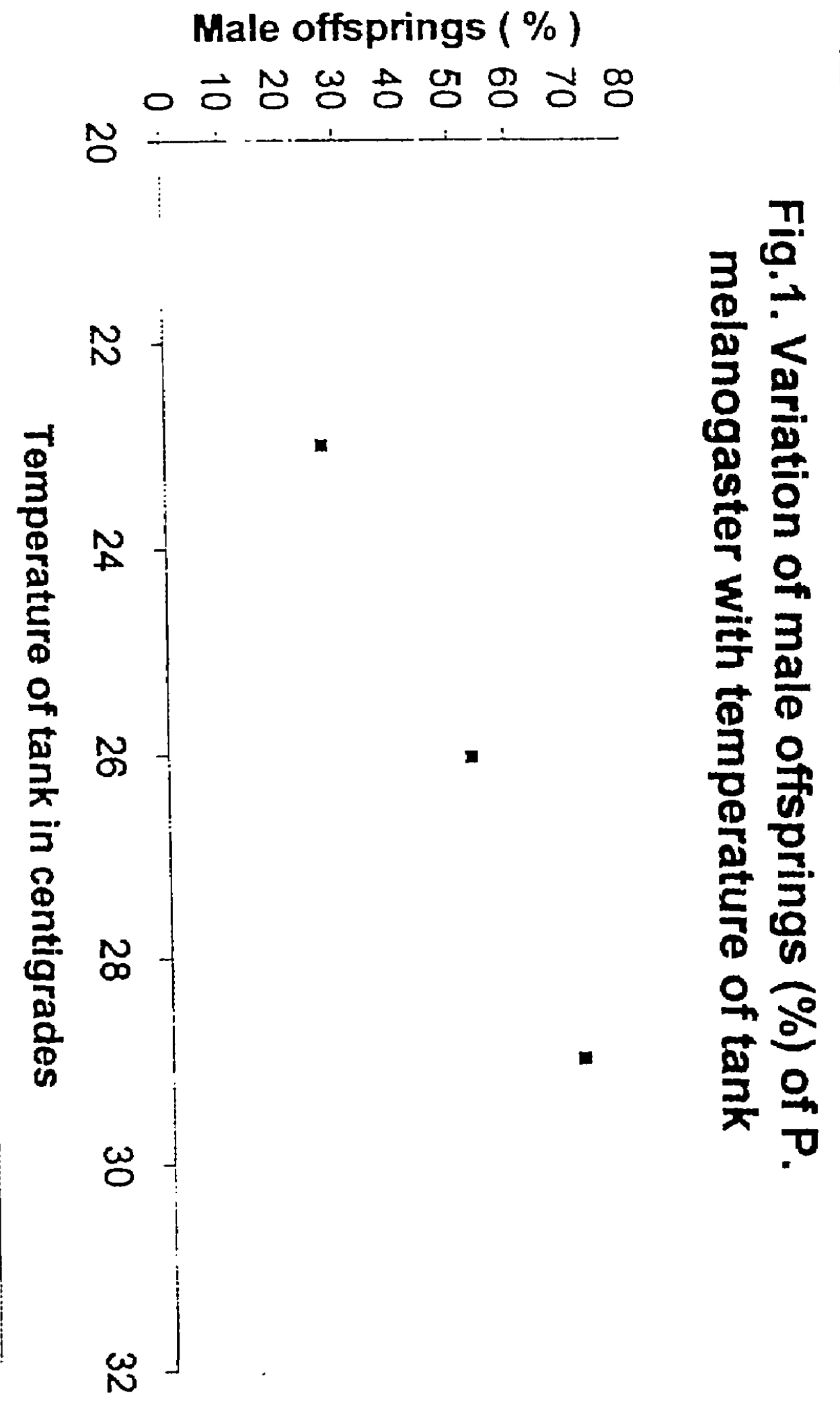


Female offsprings ( \%)

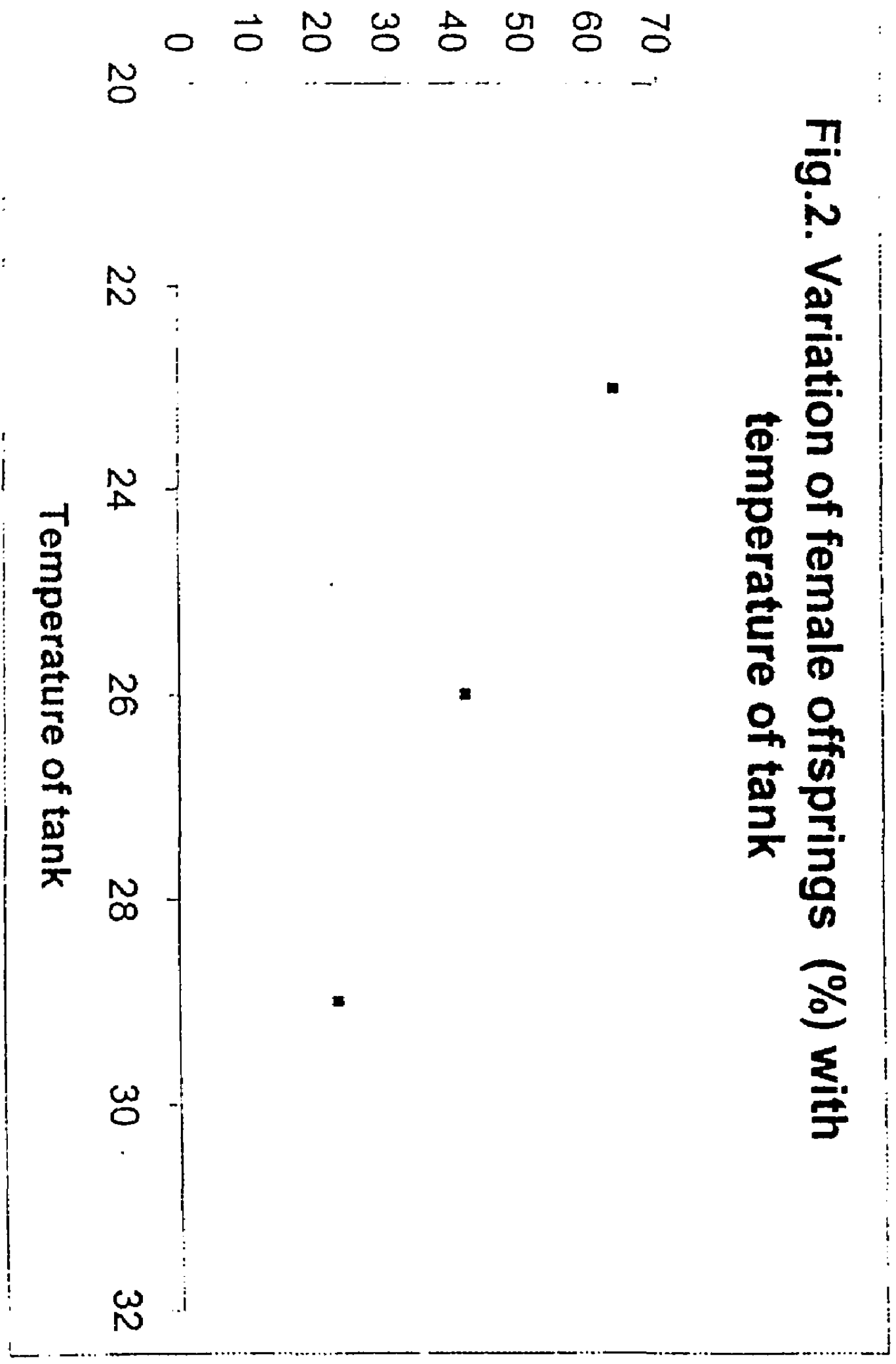


THE EFFECT OF TEMPERATURE VARLATION ON THE SEX COMPOSITION AND GROWTH OF PEOCILIA MELANOGASTER

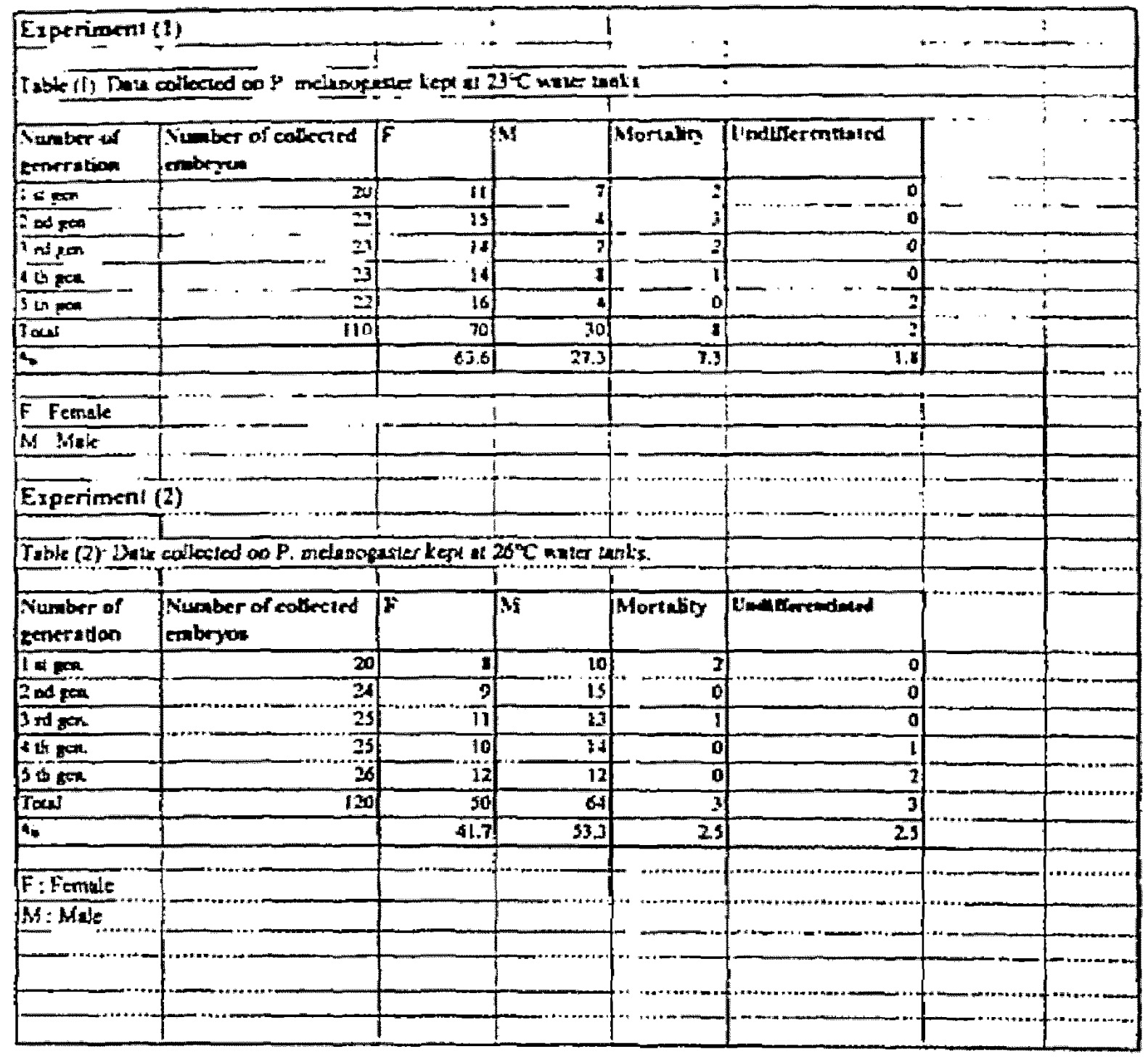




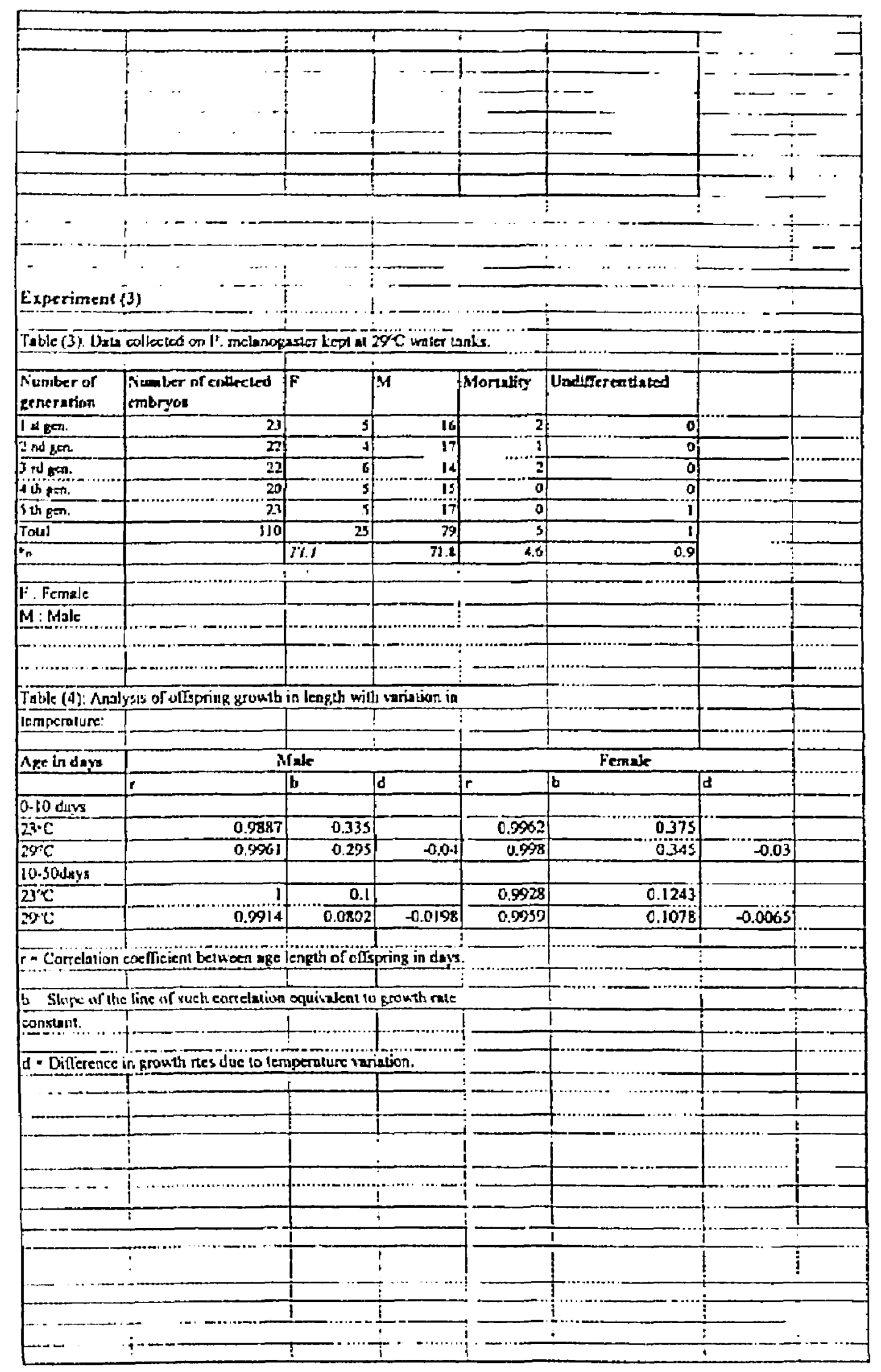

